\title{
EFEITOS DE SUBSTRATOS E DAS DIMENSÕES DOS RECIPIENTES NA QUALIDADE DAS MUDAS DE Tabebuia impetiginosa (Mart. Ex D.C.) Standl. ${ }^{1}$
}

Adriane Oliveira Cunha ${ }^{2}$, Leonaldo Alves de Andrade ${ }^{3}$, Riselane de Lucena Alcântara Bruno ${ }^{3}$, José Algaci

Lopes da Silva ${ }^{4}$ e Vênia Camelo de Souza ${ }^{5}$

\begin{abstract}
RESUMO - A crescente demanda por mudas de espécies florestais nativas tem exigido pesquisas relacionadas com o uso de substratos e recipientes, capazes de proporcionar mudas que apresentem elevadas taxas de crescimento inicial e de sobrevivência após o plantio. Este trabalho objetivou avaliar a produção de mudas de Tabebuia impetiginosa (Mart. ex D.C.) Standl (ipê-roxo), em condições acessíveis aos pequenos e médios produtores rurais. O ensaio foi instalado em área experimental localizada no Departamento de Fitotecnia (CCA/UFPB), em Areia, PB. O delineamento utilizado foi em blocos ao acaso, com 14 blocos. Os tratamentos consistiram da combinação dos substratos: $S_{1}$ - terra de subsolo e $S_{2}$ - terra de subsolo + composto orgânico e de sacos de polietileno preto nas seguintes dimensões: I - 20 x $36,5 \mathrm{~cm}$; II -15 x $32 \mathrm{~cm}$; III - 13 x $25,5 \mathrm{~cm}$; e IV - 13,5 x $19 \mathrm{~cm}$. Para todas as variáveis estudadas, o recipiente I e o substrato $\mathrm{S}_{2}$ sobressaíram em relação aos demais. Entretanto, considerando a diferença entre os resultados e a demanda de substrato e mão-de-obra exigida, no primeiro caso recomenda-se o recipiente II com o substrato $S_{2}$, para a produção de mudas dessa espécie.
\end{abstract}

Palavras-chave: Tabebuia impetiginosa, produção de mudas e sacos de polietileno.

\section{EFFECTS OF SUBSTRATA AND CONTAINERS DIMENSIONS ON THE QUALITY OF Tabebuia impetiginosa (Mart. Ex D.C.) Standl. SEEDLINGS}

\begin{abstract}
The growing demand for seedlings of native species has required research on the use of substrata and containers capable of producing seedlings with high initial growth and surviving rates after planting. This work aimed to evaluate the effects of substrata easily found in farms, and the size of containers used to produce seedlings of Tabebuia impetiginosa (Mart. ex D.C.) Standl. (Ipê roxo). The experiment was conducted in an experimental field of the Department of Agronomy-CCA/UFPB, District of Areia. The experiment was carried out in a randomized block design, totalizing 14 blocks. The treatments consisted of combinations of the following substratas: $S_{1}$-subsoil and $S_{2}$-subsoil plus organic compost and polyethylene bags with the following dimensions: I- $20 \times 36.5 \mathrm{~cm} ; \mathrm{II}-15 \times 32 \mathrm{~cm} ; \mathrm{III}-13 \times 25.5 \mathrm{~cm} ; \mathrm{IV}-13.5 \times 9 \mathrm{~cm}$. For all the studied variables, the container I and substratum $S_{2}$ gave the best results. However, considering the difference among the results and the demand for substratum and handling in the first case, it is recommended the use of container II and substratum $S_{2}$ in the production of seedlings of this species.
\end{abstract}

Keywords: Tabebuia impetiginosa, seedlings, polyethylene bags.

\footnotetext{
${ }^{1}$ Recebido em 27.08.2003 e aceito para publicação em 20.04.2005.

${ }^{2}$ Programa de Pós-Graduação em Agronomia/Fitotecnia, Rua: João Figueiredo, 469 Bodocongó 58108-143 Campina GrandePB, E-mail: <aoliveiracunha@yahoo.com.br>.

${ }^{3}$ Departamento de Fitotecnia, CCA-UFPB/Areia. E-mail: <landrade@cca.ufpb.br>.

${ }^{4}$ Centro de Ciências Agrárias - UFPI/CCA.

${ }^{5}$ Aluna de Pós-Graduação - CCA/UFPB/Areia.
} 


\section{INTRODUÇÃO}

O êxito dos projetos de reflorestamentos comerciais ou com fins conservacionistas depende, entre outros fatores, da correta escolha das espécies. Devido às múltiplas e complexas inter-relações e interações com o meio, a escolha de espécies será tanto mais correta quanto maior for o conhecimento que se tenha destas, principalmente no que se refere à ecologia e ao seu comportamento silvicultural. Os estudos sobre as espécies florestais nativas, de maneira geral, são incipientes e se relacionam, sobretudo, com as suas características botânicas e dendrológicas.

Uma das dificuldades enfrentadas por quem trabalha com a produção de mudas de espécies florestais nativas é o crescimento lento de muitas delas, particularmente daquelas classificadas como tardias ou clímax. Em face disso, é de fundamental importância a definição de protocolos e estratégias que favoreçam a produção de mudas com qualidade, em menor espaço de tempo e em condições acessíveis aos pequenos e médios produtores rurais, haja vista ser esse o público mais interessado neste tipo de insumo. Embora várias formulações de adubação já sejam conhecidas e utilizadas em viveiros florestais, não há conhecimento das exigências nutricionais da maioria das espécies nativas, acrescendo-se o fato de que o emprego dessas formulações está restrito à produção comercial de mudas; a poucos silvicultores; e, ou, a determinadas regiões do país. Por essas razões, substratos alternativos, bem como recipientes adequados, devem ser estudados, visando baratear os custos de produção e tornar o viveirismo atividade acessível a todos os produtores rurais, interessados em recompor suas áreas ou explorar alguma atividade silvicultural (JESUS, 1997; STURION e ANTUNES, 2000).

Mesmo tendo-se avançando nas técnicas de produção de mudas, ainda existem muitos problemas a serem solucionados, principalmente no que se refere ao desenvolvimento do sistema radicular das mudas, em função das características dos recipientes utilizados (MATTEI, 1999). Maior ênfase tem sido dada à pesquisa de diferentes combinações de substratos, que claramente influenciam o vigor, o desenvolvimento e a sanidade das mudas produzidas. Não obstante o mérito desses trabalhos, não se pode esquecer de que tais substratos devem ser acessíveis aos produtores rurais que, em geral, constituem um público de baixa renda. Entre os diversos materiais utilizados como substratos, é muito comum a recomendação de misturas a partir da utilização de terra, areia, raspas de madeira vermelha ou de Pinus e adubos químicos, podendo-se alterar a proporção desses materiais até certo limite. $\mathrm{O}$ aumento da quantidade de solo na mistura diminui o custo do substrato, mas aumenta o seu peso. O substrato deve ser uniforme em sua composição, ter baixa densidade, ser poroso, apresentar adequada capacidade de retenção de água e capacidade de troca catiônica (CTC) e ser isento de pragas, de organismos patogênicos e de sementes de plantas daninhas. A concentração de nutrientes na planta reflete o seu estado nutricional, estando intimamente ligada à fertilidade do solo. Embora o equilíbrio nutricional seja a situação desejável, nem sempre é possível conciliar condições ideais com viabilidade econômica (CAMPINHOS JÚNIOR e IKEMORI, 1983; GONÇALVES, 1995). Portanto, a escolha de um substrato deve considerar os aspectos técnicos, mas também a disponibilidade local do material a ser empregado.

Os resíduos orgânicos surgem como uma alternativa para diminuir os custos com a adubação química. Entre os materiais com alto potencial de utilização em viveiros, encontram-se resíduos como o bagaço de cana, as tortas, o lixo e os esgotos urbanos. Esses são materiais, em geral, ricos em sua composição química, sendo capazes de propiciar um bom desenvolvimento às plantas. Entretanto, na literatura são poucos os trabalhos que relatam a disponibilidade dos nutrientes oriundos desses materiais. Leles et al. (1998) observaram que mudas de jatobá (Hymenaea courbaril L. Var.) responderam positivamente à aplicação do bagaço de cana + torta de filtro, embora tenha ocorrido clorose durante a fase inicial de viveiro. Mudas de sabiá (Mimosa caesalpiniaefolia Benth.) e aroeira (Schinus terebinthifolius Raddi) produzidas com bagaço de cana + torta de filtro, na proporção volumétrica de $3: 2$, apresentaram o esperado crescimento em altura, diâmetro do colo, área foliar e massa seca da parte área e raiz (BARROSO et al., 1998). Ferreira et al. (1997) constataram que a adição de compostos orgânicos à terra de subsolo favoreceu o crescimento do eucalipto (Eucalyptus grandis W. Hill ex. Maiden). De acordo com Fernandes et al. (1992), o melhor substrato para a produção de mudas de Eucalyptus masculata Hook, em bandejas de isopor, foi a terra + vermiculita (2:1, para volume). Campos et al. (1986) observaram que as plantas de sibipiruna (Caesalpinia peltophoroides Benth.) produzidas nos 
substratos solo e solo + esterco, na proporção volumétrica de $1: 1$, apresentaram melhor qualidade, expressa principalmente pela relação altura/diâmetro, sendo as mudas mais adequadas para o transplantio aquelas procedentes de substratos com solo e esterco. Para a produção de mudas de Acacia mearnsii L., Caldeira et al. (2000) constataram que a dose de vermicomposto, nos recipientes utilizados, não podia ultrapassar 112 $\mathrm{cm}^{3}$, pois acima desse valor pode haver fitotoxicidade. Para o ipê-preto (Zeyhera tuberculosa Vell.), Cândido (1992) sugeriu um substrato poroso de terra de barranco acrescido de esterco de curral curtido, na proporção volumétrica de $2: 1$

Diante do exposto, o presente trabalho teve como objetivo avaliar a produção de mudas de ipê-roxo (Tabebuia impetiginosa), utilizando dois substratos de fácil acesso nas propriedades rurais, associados a diferentes dimensões de recipientes e tempo de permanência das mudas em viveiro.

\section{MATERIAL E MÉTODOS}

Local

O experimento foi realizado no Campus da Universidade Federal da Paraíba, em Areia. O clima local, pela classificação de Köppen, é do tipo AS', isto é, clima tropical, semi-úmido, com estação chuvosa no período outono-inverno. A temperatura média anual oscila entre 22 e $26^{\circ} \mathrm{C}$, a umidade relativa do ar é elevada (75 a 87\%) e a precipitação pluviométrica média anual é de 1.450 mm (BRASIL, 1972).

\section{Obtenção e avaliação das mudas}

As sementes foram provenientes de frutos de ipêroxo [Tabebuia impetiginosa (Mart. ex D.C.) Standl.] coletados em duas árvores-matrizes, de ocorrência espontânea, localizadas na Fazenda Modelo do Riachão, município de Juarez Távora, PB, no ano de 2000. Após a coleta, os frutos foram conduzidos para o Laboratório de Análise de Sementes e, em seguida, as sementes foram extraídas e armazenadas em câmara com temperatura de $18{ }^{\circ} \mathrm{C}$ e umidade relativa do ar mantida em $50 \%$, onde permaneceram por 45 dias, quando, então, foram semeadas.

Para estudar o comportamento das mudas de ipêroxo, foram utilizados sacos de polietileno preto, cujas dimensões, para diâmetro e altura, foram as seguintes, respectivamente: I) $20 \times 36,5 \mathrm{~cm}$; II) $15 \times 32 \mathrm{~cm}$; III)
13 x 25,5 cm; e IV) 13,5 x $19 \mathrm{~cm}$ e dois tipos de substratos: $\mathrm{S}_{1}$ ) terra de subsolo, coletada a partir de $20 \mathrm{~cm} \mathrm{de}$ profundidade; $\mathrm{e}_{2}$ ) terra de subsolo + composto orgânico, na proporção volumétrica de 1:1. Antecedendo à instalação do ensaio, foram caracterizados os componentes do composto orgânico e procedidas às análises químicas de ambos os substratos (Quadros 1, 2 e 3).

Quadro 1 - Características químicas do composto utilizado na produção de mudas de ipê-roxo

Table 1 - Chemical characteristics of the compost used in the production of ipê-roxo seedlings

\begin{tabular}{cc}
\hline Características Químicas $(\mathrm{g} / \mathrm{kg})$ & Valor \\
\hline $\mathrm{N}$ & 9,28 \\
$\mathrm{P}$ & 4,27 \\
$\mathrm{~K}$ & 8,48 \\
$\mathrm{Ca}$ & 8,16 \\
$\mathrm{Mg}$ & 6,67 \\
\hline
\end{tabular}

Quadro 2 - Componentes do composto orgânico utilizado na produção de mudas de ipê-roxo

Table 2 - Components of the organic compost used for the production of ipê-roxo seedlings

\begin{tabular}{lc}
\hline Componentes & Valor $(\%)$ \\
\hline Bagaço de cana-de-açúcar & 60 \\
Esterco bovino & 20 \\
Esterco de galinha & 19 \\
Cinzas & 1 \\
\hline
\end{tabular}

Quadro 3 - Caraterísticas químicas do solo e do substrato utilizado na produção de mudas de ipê-roxo

Table 3-Chemical characteristics of the soil and substratum used in the production of ip $\hat{e}$-roxo seedlings

\begin{tabular}{|c|c|c|}
\hline $\begin{array}{l}\text { Característica } \\
\text { Química* }\end{array}$ & $\begin{array}{c}\text { Terra de } \\
\text { Subsolo } * *\end{array}$ & $\begin{array}{l}\text { Terra de Subsolo + } \\
\text { Composto Orgânico }\end{array}$ \\
\hline$\overline{\mathrm{pH}}-\mathrm{H}_{2} \mathrm{O}(1: 2,5)$ & 5,6 & 7,3 \\
\hline $\mathrm{MO}\left(\mathrm{g} / \mathrm{dm}^{3}\right)$ & 31,22 & 60,26 \\
\hline $\mathrm{P}\left(\mathrm{mg} / \mathrm{dm}^{3}\right)$ & 7,46 & 863 \\
\hline $\mathrm{K}\left(\mathrm{mg} / \mathrm{dm}^{3}\right)$ & 56,0 & 126 \\
\hline $\mathrm{Na}\left(\mathrm{cmol}_{\mathrm{c}} / \mathrm{dm}^{3}\right)$ & 0,09 & - \\
\hline $\mathrm{Ca}\left(\mathrm{cmol}^{\mathrm{c}} / \mathrm{dm}^{3}\right)$ & 3,40 & 7,25 \\
\hline $\mathrm{Mg}\left(\mathrm{cmol}^{\mathrm{c}} / \mathrm{dm}^{3}\right)$ & 1,10 & 3,60 \\
\hline $\mathrm{H}+\mathrm{Al}\left(\mathrm{cmol} / \mathrm{dm}^{3}\right)$ & 4,21 & 1,49 \\
\hline $\mathrm{Fe}(\mathrm{mg} / \mathrm{kg})$ & - & 1,78 \\
\hline $\mathrm{Cu}(\mathrm{mg} / \mathrm{kg})$ & - & 0,12 \\
\hline $\mathrm{Mn}(\mathrm{mg} / \mathrm{kg})$ & - & 0,67 \\
\hline $\mathrm{Zn}(\mathrm{mg} / \mathrm{kg})$ & - & 0,17 \\
\hline $\begin{array}{l}\text { Soma de bases } \\
\left(\mathrm{cmol}_{\mathrm{c}} / \mathrm{dm}^{3}\right)\end{array}$ & 4,73 & - \\
\hline $\mathrm{CTC}\left(\mathrm{cmol}_{\mathrm{c}} / \mathrm{dm}^{3}\right)$ & 8,94 & - \\
\hline
\end{tabular}

* Análise de fertilidade realizada pelo Laboratório de Química e Fertilidade do Solo do CCA/UFPB. Extratores utilizados para micronutrientes: ácidonítrico $\left(\mathrm{HNO}_{3}\right)$ eácidoperclórico $\left(\mathrm{HCLO}_{4}\right)$ a $120^{\circ} \mathrm{C}$ eparamacronutrientes: digestão em $\mathrm{H}_{2} \mathrm{SO}_{4}$ e $\mathrm{H}_{2} \mathrm{O}_{2}$ a $180^{\circ} \mathrm{C}$, conforme Tedesco (1995).

** Análise quî́mica da terra de subsolo realizada no momento da instalação do experimento.

R. Árvore, Viçosa-MG, v.29, n.4, p.507-516, 2005 
A assepsia das sementes fora realizada imergindoas em solução de hipoclorito de sódio $5 \%$, durante cinco minutos, lavando-as, em seguida, com água destilada. A semeadura foi realizada colocando-se quatro sementes por recipiente. Após a emergência, realizouse o desbaste das plântulas em excesso, permanecendo apenas uma por recipiente. A umidade dos substratos foi mantida com regas periódicas, sempre que necessário.

Como parâmetros de avaliação, foram medidos o diâmetro do colo e a altura das plantas, a cada 60 dias, durante o tempo de duração do ensaio, sendo o intervalo decorrido entre a penúltima e a última leitura de apenas 30 dias. Por ocasião da coleta do experimento, as plantas foram seccionadas em parte aérea e sistema radicular, efetuando-se a medição do comprimento da raiz principal e o diâmetro na posição intermediária desta, utilizandose para isso régua milimetrada e paquímetro de precisão. O material seccionado foi acondicionado em sacos de papel e posto para secar em estufa a $60^{\circ} \mathrm{C}$ até atingir peso constante. Em seguida, determinou-se, através de balança eletrônica, o peso da massa seca, em gramas.

O delineamento estatístico utilizado foram blocos casualizados, com oito tratamentos e 14 repetições, sendo, nas variáveis altura e diâmetro do colo das plantas, o delineamento estatístico em parcelas subdivididas no tempo, estando estas representadas pelos tratamentos ( 8 tratamentos) e as subparcelas, pelos períodos (6 períodos) de avaliação das plantas.

Foram determinados os efeitos isolados de recipiente e substrato, bem como as interações de segunda ordem das variáveis: peso de massa seca da parte aérea e raiz, comprimento de raiz principal e diâmetro de raiz principal. As médias foram comparadas pelo teste de Tukey a 5\%. Os dados foram submetidos à análise de variância com desdobramento das somas de quadrado dos efeitos em regressão linear. Em ambas as análises, utilizou-se o Sistema para Análise Estatística SAEG 8.3.

\section{RESULTADOS E DISCUSSÃO}

\section{Altura de plantas e diâmetro do colo}

De acordo com a análise de regressão, o efeito da interação substrato $\mathrm{x}$ recipiente foi significativo na altura de plantas, apresentando comportamento linear crescente (Figura $1 \mathrm{ABCD}$ ). Constatou-se que as plantas provenientes do tratamento com composto orgânico no recipiente maior $(20 \times 36,5 \mathrm{~cm})$ atingiram, em torno dos 180 dias, altura superior a $15 \mathrm{~cm}$. Embora o tempo de permanência das mudas no viveiro possa ser considerado relativamente longo, ressalta-se que neste trabalho o propósito foi desenvolver um protocolo de baixo custo e de fácil acesso para produtores rurais de baixa renda. Certamente, esse tempo de permanência poderá ser diminuído, a partir do emprego de substratos de maior fertilidade e, ou, do emprego de formulações de adubação química que poderão ser desenvolvidas para essa espécie.

O efeito significativamente positivo do substrato enriquecido com composto orgânico no crescimento em altura de mudas pode estar relacionado com a maior disponibilidade de $\mathrm{P}, \mathrm{Ca}, \mathrm{Mg}$ e $\mathrm{K}$ e com o $\mathrm{pH}$, situado em níveis adequados ao desenvolvimento das plantas (Quadro 3). Diversos autores têm comprovado que a adição de composto orgânico aos substratos usados para produção de mudas resulta em benefícios como o fornecimento de macro e micronutrientes e a redução do Al trocável. Mudas de oiti (Licania tomentosa Benth.) atingiram as maiores médias em altura de plantas, segundo Alves e Passoni (1997), quando cultivadas em substrato acrescido de composto orgânico e vermicomposto. Campos et al. (1986), estudando a influência do substrato no desenvolvimento inicial de mudas de sibipiruna (Caesalpinia peltophoroides Benth.), concluíram que as plantas com melhor aparência (maior altura e diâmetro) foram aquelas originadas dos substratos solo e solo + esterco bovino, na proporção de 1:1, para volume. Nesse sentido, Canellas et al. (2001) assinalaram que a incorporação de resíduos procedentes do lixo urbano em Latossolo Vermelho-Amarelo e Argissolo Vermelho-Amarelo promoveu aumento nos teores de $\mathrm{Ca}$ e $\mathrm{Mg}$, refletindo no desenvolvimento das mudas de ipê-roxo.

No que tange ao efeito do tamanho do recipiente sobre a altura das plantas, é notável, neste trabalho, o desenvolvimento das mudas nos recipientes de maiores dimensões ( $20 \times 36,5 \mathrm{~cm}$ e $15 \times 32 \mathrm{~cm}$ ) (Figura 1AB). Resultados semelhantes foram encontrados por outros autores, em diferentes espécies arbóreas. Mudas de camu-camu (Myrciaria dubia L.) produzidas em sacos de polietileno preto de 19 x $21 \mathrm{~cm}$ mostraram tendência de melhor desenvolvimento quando comparadas com outras cultivadas em recipientes menores (YUYAMA e SIQUEIRA, 1999). Nesse sentido, Oliveira et al. (2000) observaram que mudas de cajueiro propagadas em sacos de polietileno apresentaram altura estatisticamente superior a mudas da mesma espécie, propagadas em tubetes, com volumes inferiores aos dos sacos. 

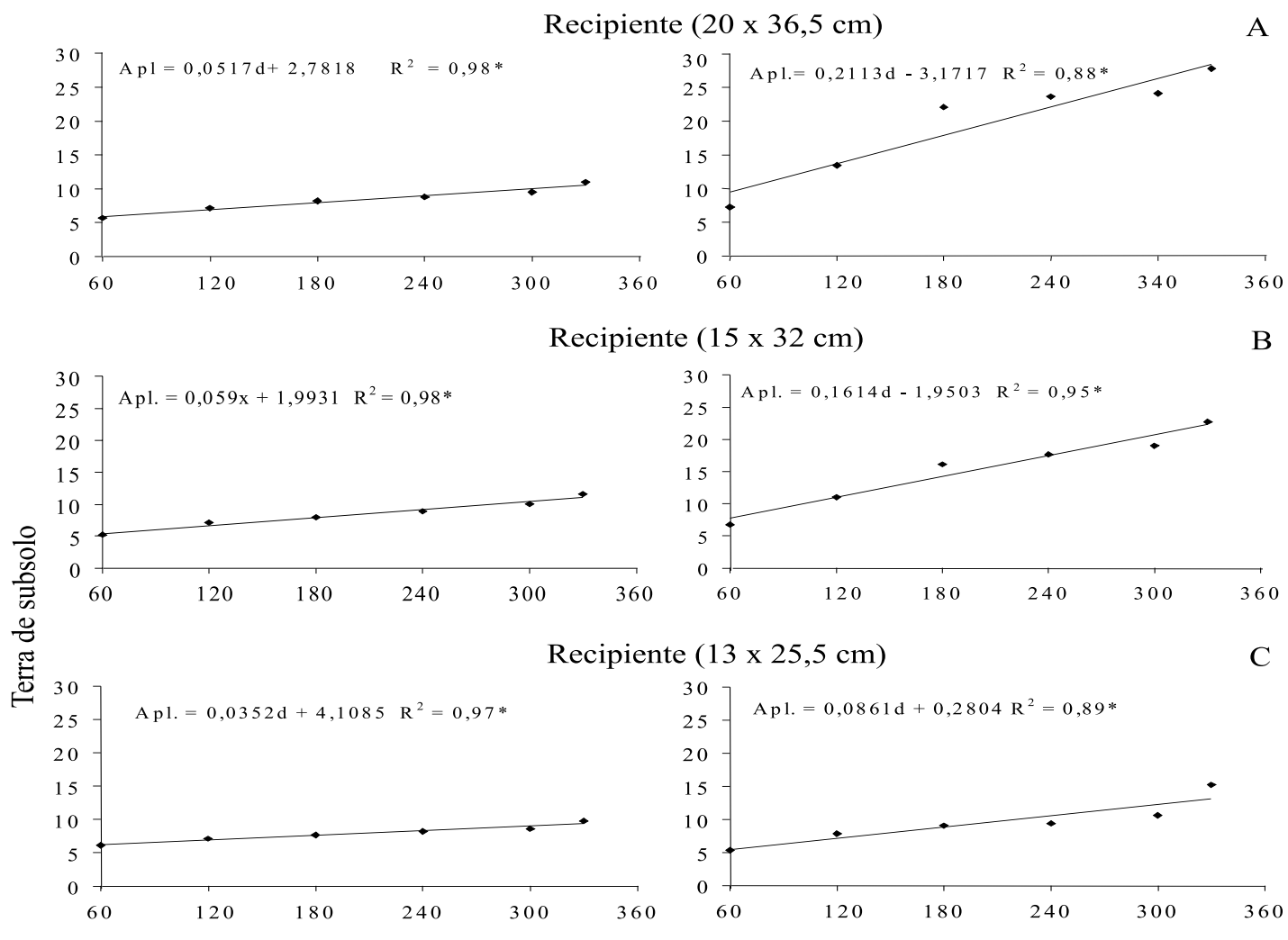

Recipiente $(13,5 \times 19 \mathrm{~cm})$
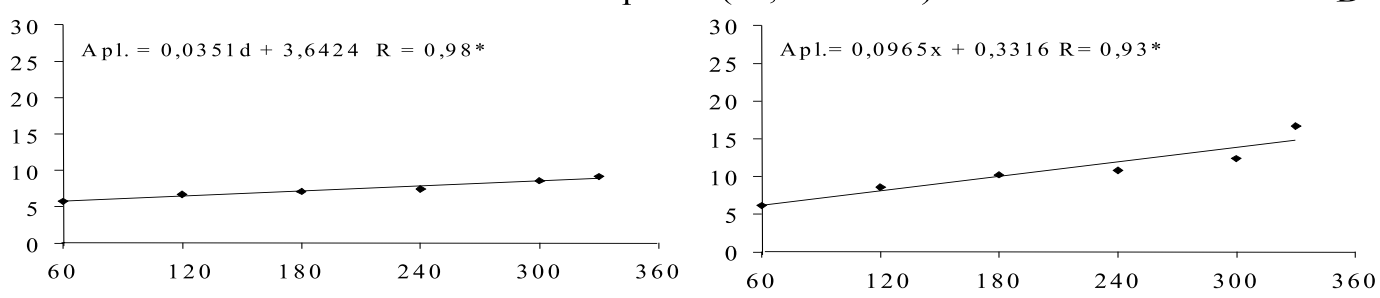

Dia após a semeadura

Figura 1 - Efeito dos substratos e dos recipientes sobre a altura de mudas de ipê-roxo aos 330 dias após a semeadura. Figure 1 - Effect of substrata and containers on the height of ipê-roxo seedlings up to 330 days after sowing.

Em relação ao diâmetro do colo, verificou-se que as curvas de regressão ajustadas para esse parâmetro revelam efeito linear para a interação substratos $\mathrm{x}$ recipientes (Figura 2A-D). As plantas cultivadas apenas com terra de subsolo apresentaram diâmetro do colo sempre inferior ao daquelas que receberam composto orgânico (substrato $S_{2}$ ). Nesse substrato, aos 180 dias o diâmetro do colo das plantas já se apresentava superior a $6 \mathrm{~mm}$, nos recipientes I e II.
De acordo com Sturion e Antunes (2000), a relação altura/diâmetro do colo constitui um dos parâmetros usados para avaliar a qualidade de mudas florestais, pois, além de refletir o acúmulo de reservas, assegura maior resistência e melhor fixação no solo. Mudas com baixo diâmetro do colo apresentam dificuldades de se manterem eretas após o plantio. O tombamento decorrente dessa característica pode resultar em morte ou deformações que comprometem o valor silvicultural

R. Árvore, Viçosa-MG, v.29, n.4, p.507-516, 2005 
dos indivíduos. Mudas que apresentam diâmetro do colo pequeno e alturas elevadas são consideradas de qualidade inferior às menores e com maior diâmetro do colo. Essa variável é reconhecida como um dos melhores, se não o melhor indicador do padrão de qualidade de mudas (MOREIRA e MOREIRA, 1996), sendo, em geral, o mais indicado para determinar a capacidade de sobrevivência de mudas no campo (DANIEL et al., 1997).

Os resultados evidenciam que a adição do composto orgânico, de baixo custo, preparado a partir de material disponível nas propriedades rurais, resulta em benefícios à qualidade das mudas e, consequientemente, em ganhos para o produtor. Assim como na altura de plantas, as dimensões dos recipientes também exerceram influência sobre o incremento do diâmetro do colo, pois os maiores diâmetros foram obtidos nos maiores recipientes, em ambos os substratos.

\section{Peso da massa seca da parte aérea e da raiz}

Ao considerar a interação substrato x recipiente, pode-se observar na Figura 3 que foram encontradas diferenças significativas entres os substratos nos pesos de massa seca da parte aérea e do sistema radicular das mudas de ipê-roxo. Comparando-se os recipientes, não houve diferença significativa entre estes quanto à massa seca da parte área ao se utilizar o substrato $\mathrm{S}_{1}$. No entanto, as plantas cultivadas no recipiente I com substrato $S_{2}$ sobressaíram em relação às demais, enquanto os recipientes III e IV apresentaram os piores resultados. Com relação ao substrato $\mathrm{S}_{2}$, constatouse que o recipiente I foi o responsável pelo maior valor da massa seca, embora a diferença não tenha sido estatisticamente significativa na massa seca da parte aérea. Pode-se afirmar, contudo, que as mudas de ipêroxo responderam, de modo positivo, à incorporação do composto orgânico. Os recipientes III e IV, novamente, apresentaram resultados com valores inferiores.

Resultados semelhantes foram relatados por Barroso et al. (1998), que obtiveram maior massa seca de raiz em mudas de aroeira e sabiá cultivadas em substrato constituído por bagaço de cana e torta de filtro, na proporção volumétrica de 3:2. Também Tedesco et al. (1999) constataram aumento linear no peso seco da parte aérea e do sistema radicular, utilizando doses crescentes de vermicomposto. Para Clement e Machado (1997), a melhor resposta ocorreu sob a influência de $10 \mathrm{~kg}$ de composto orgânico por $\mathrm{m}^{2}$, incorporado ao solo, produzindo $0,55 \mathrm{~kg} / \mathrm{m}^{2}$ de biomassa seca total em quebra-pedra (Phyllanthus stipulatus, Euphorbiaceae). De acordo com Jesus et al. (1991), as dimensões do recipiente e o tipo de substrato influenciam a qualidade das mudas, e isso se deve, possivelmente, ao fato de esses elementos estarem diretamente relacionados com disponibilidade de espaço físico e aporte de nutrientes, condições essenciais para o cultivo de plantas ex situ.

\section{Comprimento e diâmetro de raiz principal}

Observando a Figura 4, constatou-se que as dimensões dos recipientes influenciaram o comprimento da raiz principal, cujas diferenças foram estatisticamente significativas nos recipientes I e II. Ainda na Figura 4 , constata-se que o menor comprimento da raiz principal ocorreu nos recipientes III e IV, os quais foram estatisticamente equivalentes. Igualmente, o substrato $\mathrm{S}_{2}$ (terra de subsolo + composto orgânico) proporcionou maior diâmetro da raiz principal, sugerindo maior reserva de nutrientes (Figura 5).

Recipientes de maiores volumes oferecem melhores condições para o desenvolvimento das mudas, contudo esses somente devem ser utilizados para espécies que apresentam desenvolvimento lento, necessitando permanecer no viveiro por um longo tempo, ou quando se deseja mudas bem desenvolvidas, para plantio em vias públicas, por exemplo. Deve-se considerar que as demandas de insumos, mão-de-obra e transporte impõem limites às dimensões dos recipientes destinados à produção de mudas, exigindo que se estabeleça, necessariamente, a melhor relação custo/benefício. No entanto, a escolha inadequada do recipiente pode causar deformações no sistema radicular que, por sua vez, contribui para reduzir a capacidade de translocação dos nutrientes. Tais resultados corroboram com os relatos de Cândido e Gomes (1993), que sugerem o uso de recipientes plásticos de altura maior que o diâmetro para o ipê-felpudo (Zeyhera tuberculosa Vell. Bur.), em função do potencial crescimento de sua raiz pivotante. Segundo Mattei (1999), a capacidade de estabelecimento e de competição de uma espécie florestal, em determinado ambiente, depende, em grande parte, do tamanho, da forma, do tipo e da eficiência do sistema radicular. Novaes et al. (1998), avaliando a qualidade de mudas de Pinus taeda, produzidas em raiz nua e em diferentes tipos de recipientes, encontraram correlação positiva entre o comprimento total e o número de novas raízes, com a altura e diâmetro das mudas alcançados aos 24 meses após o plantio. 
Terra de subsolo

Terra de subsolo + composto orgânico
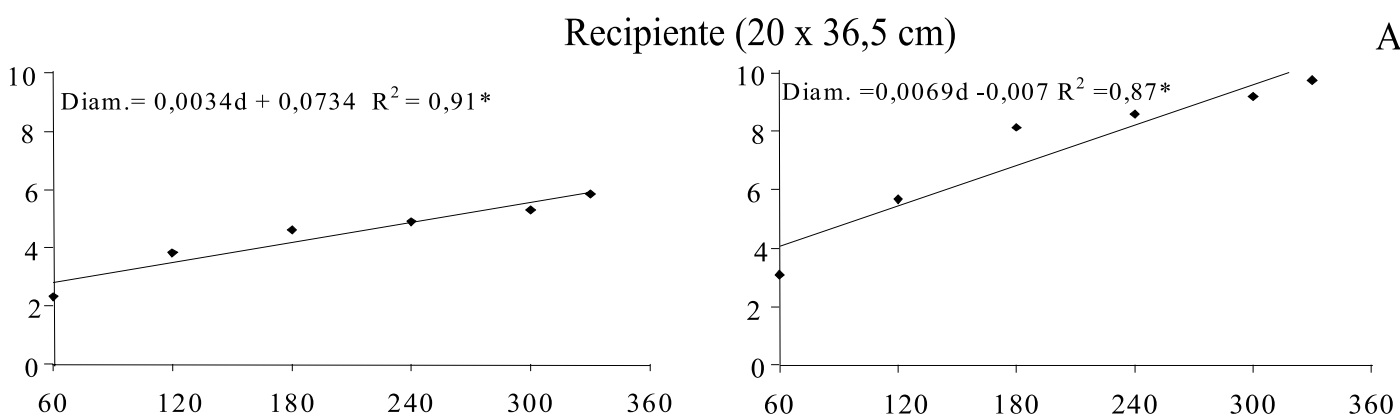

Recipiente $(15 \times 32 \mathrm{~cm})$

B
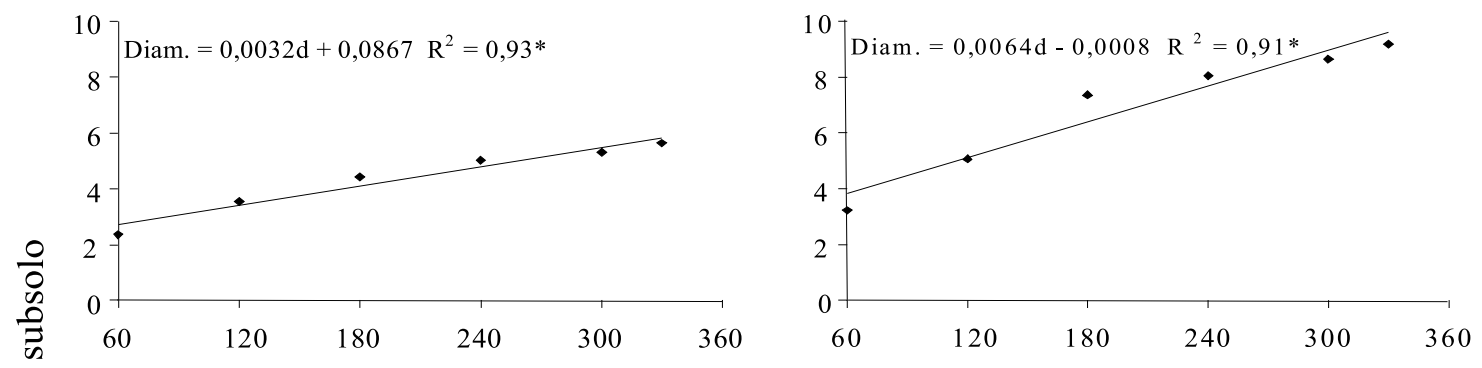

Recipiente $(13 \times 25,5 \mathrm{~cm})$

C
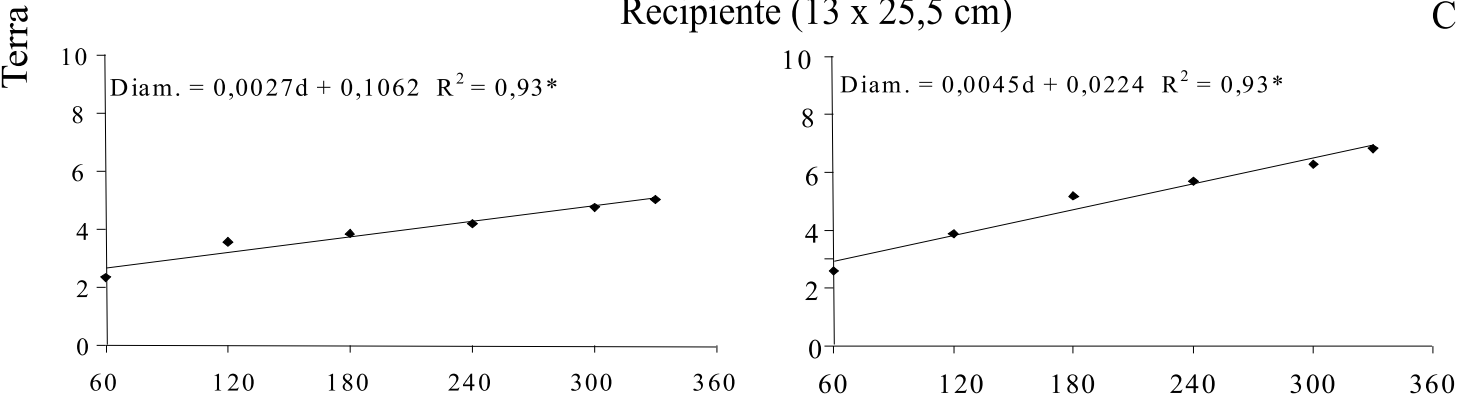

Recipiente $(13,5 \times 19 \mathrm{~cm})$

D
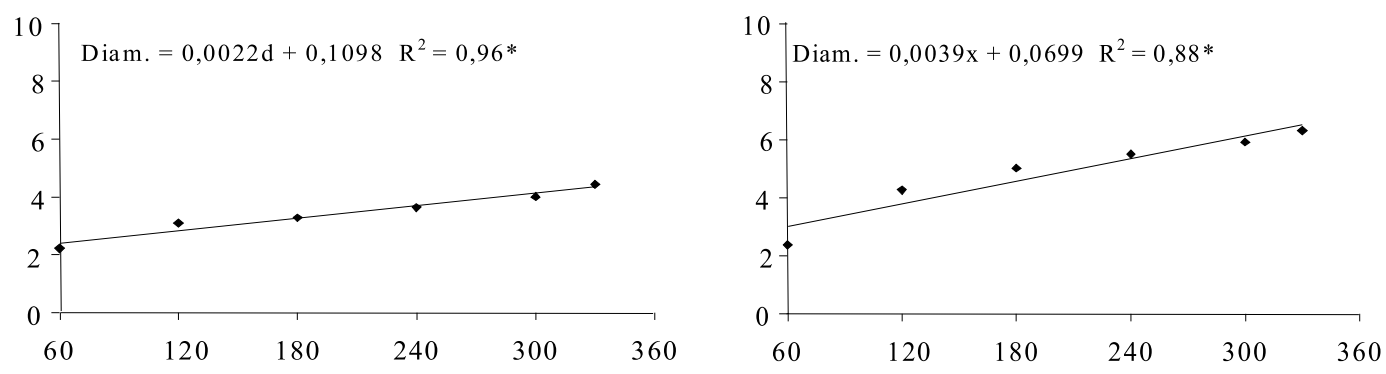

Dia após a semeadura

Figura 2 - Efeito dos substratos e dos recipientes sobre o diâmetro do colo de mudas de ipê-roxo aos 330 dias após a semeadura. Figure 2-Effect of substrata and containers on the diameter of ipê-roxo seedlings up to 330 days after sowing. 

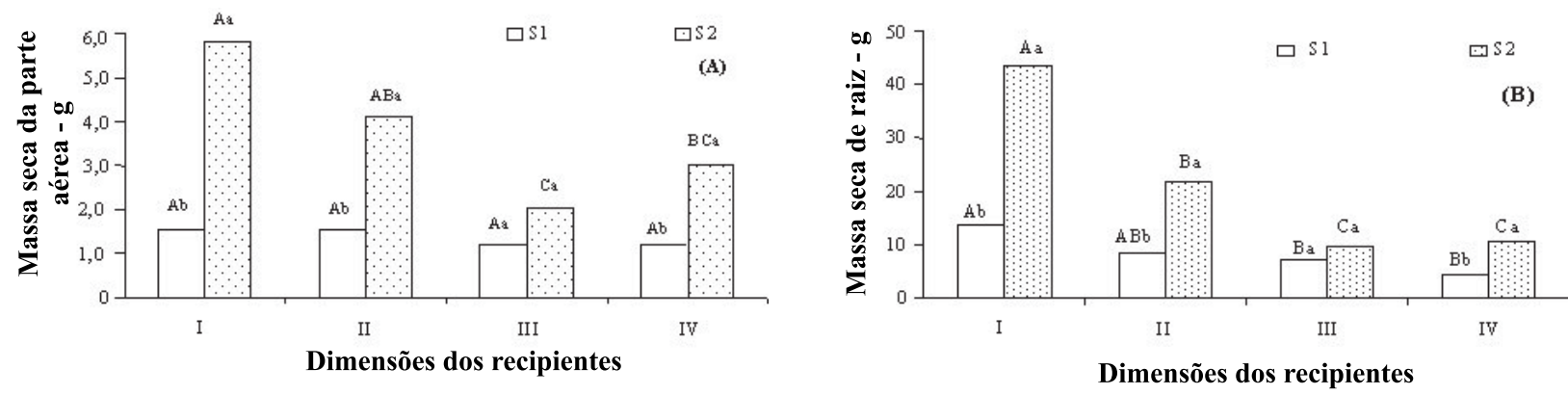

Figura 3 - Efeito do recipiente sobre a massa seca da parte aérea (A) e radicular (B) de mudas de ipê-roxo aos 330 dias após a semeadura. Letras minúsculas comparam substratos em cada tamanho de recipiente. Letras maiúsculas comparam dimensões de recipientes em cada substrato. S1-terra de subsolo; S2-terra de subsolo + composto orgânico; I-20 x 36,5 cm; II- $15 \times 32 \mathrm{~cm}$; III- $13 \times 25,5 \mathrm{~cm}$; e IV- $13,5 \times 19 \mathrm{~cm}$.

Figure 3 - Effect of the container on the dry mass of shoot $(A)$ and root $(B)$ of ipê-roxo seedlings up to 330 days after sowing. Small letters compare substrata of each container size. Capital letters compare container sizes of each substratum. S1-subsoil; S2- subsoil +organic compost; I-20 x 36.5cm, II-15 $\times 32 \mathrm{~cm}, I I I-13 \times 25.5 \mathrm{~cm}, I \mathrm{~V}-13.5 \times 19 \mathrm{~cm}$.

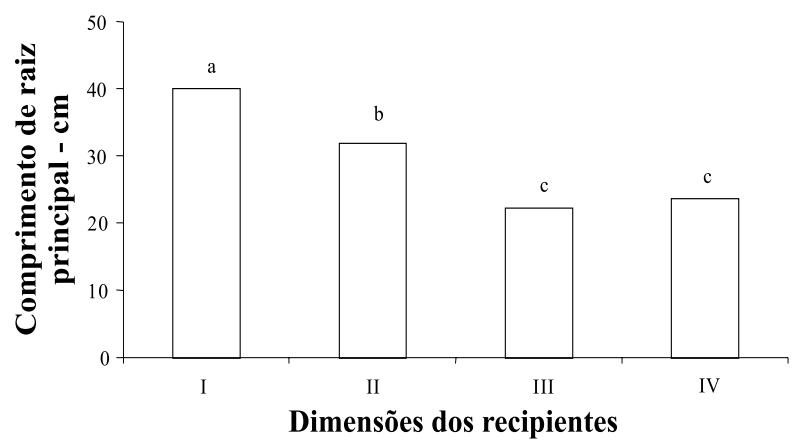

Figura 4 - Efeito dos recipientes sobre comprimento de raiz principal de mudas de ipê-roxo aos 330 dias após a semeadura. I- 20 x $36,5 \mathrm{~cm}$; II- 15 x $32 \mathrm{~cm}$; III$13 \times 25,5 \mathrm{~cm} ;$ e IV- $13,5 \times 19 \mathrm{~cm}$.

Figure 4-Effect of containers on the main root length of ipê-roxo seedlings up to 330 days after sowing. $I-20 \times 36.5 \mathrm{~cm}, I I-15 \times 32 \mathrm{~cm}, I I I-13 \times 25.5 \mathrm{~cm}$, IV $-13.5 \times 19 \mathrm{~cm}$.

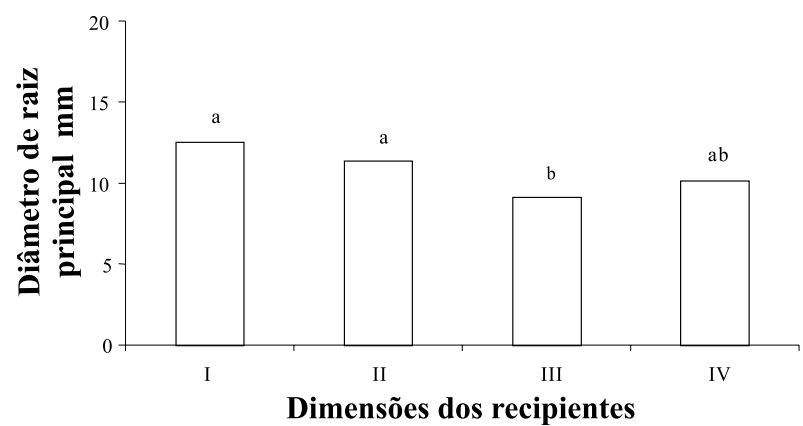

\section{CONCLUSÕES}

Mudas de ipê-roxo podem ser satisfatoriamente produzidas em sacos de polietileno de $15 \times 32 \mathrm{~cm}$, utilizando o substrato terra de subsolo + composto orgânico, produzido com material de baixo custo, geralmente disponível no próprio meio rural.

Recipientes menores reduzem a taxa de crescimento das mudas, implicando aumento do ciclo de produção.

O substrato terra de subsolo não atendeu às exigências nutricionais da espécie em viveiro.

O protocolo avaliado proporcionou, aos 180 dias, mudas com altura e diâmetro do colo recomendados para plantio. Para a redução do tempo de permanência das mudas em viveiro, faz-se necessário avaliar outros substratos e, ou, formulações de adubação química, cuja utilização extrapola os objetivos deste trabalho.

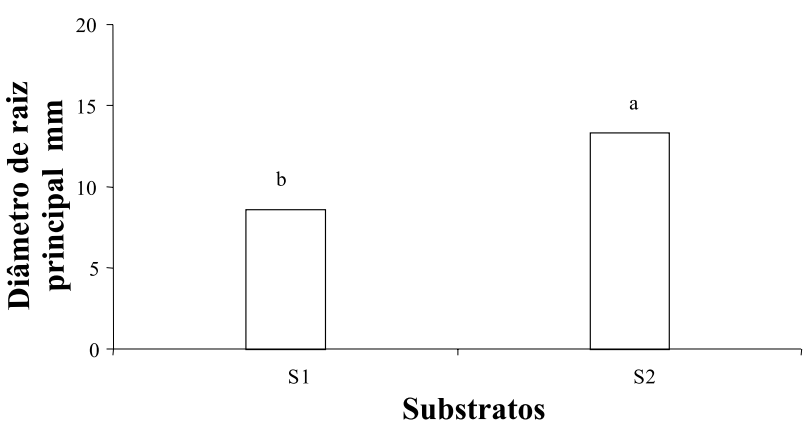

Figura 5 - Efeito isolado de substrato e do recipiente sobre o diâmetro de raiz principal de mudas de ipê-roxo aos 330 dias após a semeadura. S1- terra de subsolo; S2- terra de subsolo + composto orgânico; I-20 x 36,5 cm; II-15 x $32 \mathrm{~cm}$; III-13 x $25,5 \mathrm{~cm}$; IV- 13,5 x $19 \mathrm{~cm}$.

Figure 5 - Isolated effect of the substratum and container on the main root diameter of ipê-roxo seedlings up to 330 days after sowing. S1- subsoil; S2-subsoil + organic compost; $I-20 \times 36.5 \mathrm{~cm}, I I-15 \times 32 \mathrm{~cm}, I I I-13 \times 25.5 \mathrm{~cm}, I V-$ $13.5 \times 19 \mathrm{~cm}$.

R. Árvore, Viçosa-MG, v.29, n.4, p.507-516, 2005 


\section{REFERÊNCIAS BIBLIOGRÁFICAS}

ALVES, W.L.; PASSONI, A.A. Composto e vermicomposto de lixo urbano na produção de mudas de oiti (Licania tomentosa Benth.) para arborização. Pesquisa Agropecuária Brasileira, v. 32, n. 10, p. 58-62, 1997.

BARROSO, D.G. et al. Efeito da adubação em mudas de sabiá (Mimosa caesalpiaenifolia Benth.) e aroeira (Schinus terebinthifolius Raddi.) produzidas em substrato constituído por resíduos agroindustriais. Revista Árvore, v. 22, n. 4, p. 433-441, 1998.

BRASIL. Ministério da Agricultura.

Levantamento exploratório, reconhecimento de solos do Estado da Paraíba. Rio de Janeiro: MA/CONTA/USAID/ SUDENE, 1972, 670p. (Boletim Técnico, 15).

CALDEIRA, M.V.W.; SCHUMACHER, M.V.; TEDESCO, N. Crescimento de mudas de Acacia mearnisii $\mathrm{L}$. em função de diferentes doses de vermicomposto. Scientia Forestalis, n. 57, p. 161-170, 2000.

CAMPINHOS JÚNIOR, E.; IKEMORI, Y.K. Introdução de novas técnicas na produção de mudas de essências florestais. Silvicultura, v. 8, n. 28, p.226, 1983.

CAMPOS, L. A. A. et al. A Influência de profundidade de semeadura e substratos no desenvolvimento inicial de sibipiruna (Caesalpinia peltophoroides Benth.). Científica, v. 14, n. 1/2, p. 101-113, 1986.

CÂNDIDO, J.F. Culturas de espécies florestais I. Viçosa: SIF, 1992. 115p. (Documento SIF).

CÂNDIDO, J.F.; GOMES, J.M. Introdução as novas técnicas na produção de viveiros florestais II. Viçosa: ISF, 1993. 144p. (Documento SIF).

CANELLAS, L.P. et al. Distribuição da matéria orgânica e características de ácidos húmicos em solos com adição de resíduos de origem urbana. Pesquisa Agropecuária Brasileira, v. 36, n. 12, p. 1529-1538, 2001.
CLEMENT, C.R.; MACHADO, F.M. Efeito da adubação orgânica na produção de biomassa em quebra-pedra (Phyllanthus stipulatus,

Euphorbiaceae) em Manaus, Brasil. Acta

Amazônica, v. 27, n. 2, p. 73-80, 1997.

DANIEL, O. et al. Aplicação de fósforo em mudas de Acacia mangium Willd. Revista Árvore, v. 21 , n. 2, p. 163-168, 1997.

FERNANDES, P. S.F.; COUTINHO, C.J.; BAENA, E. S. Produção de mudas de Eucalyptus masculata Hook em bandejas de isopor. In: CONGRESSO FLORESTAL BRASILEIRO, 4., 1982. Belo Horizonte. Anais... Belo Horizonte: Sociedade Brasileira de Silvicultura, 1992. p. 145155.

FERREIRA, M. G.M.; CANDIDO, J.F.; CANO, M.A.O. Efeito do sombreamento na produção de mudas de quatro espécies florestais nativas - I: Germinação. Revista Árvore, v. 1, n. 2, p. 6167, 1997.

GONÇALVES, J.L. M. Recomendações de Adubação para Eucalyptus, Pinus e Espécies Típicas da Mata Atlântica. Piracicaba: 1995. 15p. (Documentos florestais, 23).

JESUS, B.M. Morfologia de sementes, germinação e desenvolvimento de mudas de angico de bezerro (Piptadenia obliqua (Pers.) Macbr.). 1997. 81f.

Dissertação (Mestrado em Produção Vegetal) Universidade Federal da Paraíba, Areia, 1997.

JESUS, R.; LOGISTER, F.; MENANDRO, M.S. Efeito da luminosidade e do substrato na produção de mudas de Cordia trichotoma Vell. In: CONGRESSO FLORESTAL ESTADUAL, 4. 1991, Nova Prata. Anais ... Nova Prata: 1991. v.1, p. $459-479$.

LELES, P.S.S.; CARNEIRO, J.G.A.; BARROSO, D.G. Comportamento de mudas de Hymanaea courbaril L. var. Stibocarpa (Haime) e Apuleia leiocarpa (Vog.) Macbr. produzidas sob três regimes de irrigação. Revista Árvore, v. 22, n. 1, p. 11-19, 1998.

R. Árvore, Viçosa-MG, v.29, n.4, p.507-516, 2005 
MATTEI, V.L. Deformações radiculares em plantas de Pinus taeda L. produzidas em tubetes quando comparadas com plantas originadas por semeadura direta. Ciência Florestal, v. 4, n. 1, p. 1-9, 1999.

MOREIRA, F. M. S.; MOREIRA, F. W.

Característica de germinação de 64 espécies de leguminosas florestais nativas da Amazônia, em condições de viveiro. Acta Amazônica, v. 26, n. 1/2, p. 3-16, 1996.

NOVAES, R.F; REGO, A.K.; GOMES, J.M. Nível crítico de potássio no solo e na planta para o crescimento de mudas de Pinus taeda. Revista Árvore, v.4, p.14-23, 1998.

OLIVEIRA, V.H.; LIMA, R.N.; PINHEIRO, R.D. Efeito do recipiente utilizado na formação de mudas no crescimento e desenvolvimento de plantas de cajueiro cultivadas sob irrigação. EMBRAPA, 2000. 3p. (EMBRAPA.Pesquisa em andamento, 72).
STURION; J.A.; ANTUNES, B.M.A. Produção de mudas de espécies florestais. In: GALV ÃO, A.P.M. Reflorestamento de propriedades rurais para fins de produtivos e ambientais, Colombo: 2000. p.125-150.

TEDESCO, M.J. Análise de solo, planta e outros materiais. 2. ed. Porto Alegre:

Universidade Federal do Rio Grande do Sul, 1995. 174p.il. (Boletim Técnico, 5).

TEDESCO, N.; CALDEIRA, M.V.W.; SCHUMACHER, M.V. Influência do vermicomposto na produção de mudas de caroba (Jacaranda micrantha Chamisso). Revista Árvore, v. 23, n. 1, p. 1-8, 1999.

YUYAMA, K.; SIQUEIRA, J. A. S. Efeito do tamanho das sementes e do recipiente no crescimento de mudas de camu-camu (Myrciaira dubia). Acta Amazônica, v. 29, n. 4, p. 647 650, 1999. 